\title{
An Integrated Approach for Predicting Consumer Acceptance of Self-Driving Vehicles in the United States
}

\author{
Kevin Elliott \\ Minnesota State University Mankato \\ Juan (Gloria) Meng \\ Minnesota State University Mankato \\ Mark Hall \\ Minnesota State University Mankato
}

\begin{abstract}
Recent advances in automotive automation technology have made self-driving vehicles technically feasible. As automotive technology continues to evolve, self-driving vehicles are projected to be available for purchase within the United States by 2030. This study proposes and tests an integrated consumer adoption model in an effort to better understand factors that may influence a consumer's intention to use a selfdriving vehicle. An 18-item questionnaire was developed for this study. A survey was then conducted using Qualtrics $(n=1,050)$. Results show that facilitating conditions significantly impact both performance expectancy and effort expectancy of self-driving vehicles. The resulting performance expectancy and effort expectancy subsequently have a strong influence on attitude towards a self-driving vehicle. Attitude then directly impacts the intention to use a self-driving vehicle. Implications are discussed that should be beneficial to marketers of self-driving vehicles.
\end{abstract}

Keywords: self-driving vehicles, autonomous technology, future automobiles

\section{INTRODUCTION}

During the last decade there have been considerable developments in automated vehicle technology. Kaplan et al. (2019, p. 594) argue that the introduction of self-driving vehicles will reshape the transportation system, and "there will likely be an increase in miles traveled per capita, more vehicles on the road, increased sprawl, and expansion to include users currently facing limited mobility." The National Highway Traffic Safety Administration has identified four potential benefits of self-driving vehicles: safety, economic and social benefits, efficiency and convenience, and mobility (National Highway Traffic Safety Administration, 2020).

The U.S. federal government has begun to establish guidelines and regulations to prepare for the introduction of automated vehicle technology. The government publication, Ensuring American Leadership in Automated Vehicle Technologies (2020), explains that the federal government will provide guidance and best practices, conduct research and pilot programs, and provide other assistance to help stakeholders 
plan and make investments for the introduction of automated vehicle technology in the coming decades. In addition, the federal government plans to fund automated vehicle technology research in the areas of safety, mobility, security and cybersecurity, infrastructure, and connectivity.

The purpose of this study is to test the theoretical underpinnings of a proposed consumer adoption model for self-driving vehicles. Multiple factors may contribute to positive consumer perception and a willingness to accept self-driving vehicles (Nordhoff et al., 2018). Understanding and predicting consumer acceptance of self-driving vehicles within the U.S. requires theory-grounded models that capture key factors impacting a consumer's attitude towards these vehicles. Factors included in this study incorporate variables from: 1) Venkatesh et al., (2003) - UTAUT (United Theory of Acceptance and Use of Technology; 2) Hewitt et al. (2019) - AVAM (Autonomous Vehicle Acceptance Model); 3) Nordhoff et al. (2019) - MAVA (Multi-Level Model on Automated Vehicle Acceptance); and 4) Osswald et al. (2012) - CTAM (Car Technology Acceptance Model).

For self-driving vehicles to be fully accepted, not only will technology infrastructure, related public policies, and government funding need to be developed, but also an understanding of consumer attitudes towards the concept. Consumer attitudes will be a critical factor in the adoption process for self-driving vehicles. Currently, U.S. marketers have limited information regarding key factors that impact consumer attitudes toward new automated vehicle technology. This study is one of the first to present and test a theoretical model based on previous technology acceptance models using U.S. consumers as respondents. The findings of this study should help marketers better understand factors likely to influence consumer adoption of self-driving vehicles as these vehicles become available within the United States.

\section{LITERATURE REVIEW}

\section{Self-Driving Vehicles}

A self-driving vehicle has been commonly defined as a computer-controlled vehicle that drives itself. U.S. regulators and the Society of Automotive Engineers (SAE) have identified the following six levels/stages of driving automation:

- SAE Level 0 (No automation): human driver is at the control of the driving task even when equipped with warning and/or intervention systems.

- SAE Level 1 (Driver assistance): human driver performs all aspects of the dynamic driving task when automated system can assist the driver with one driver assistance system of either steering or acceleration/deceleration.

- SAE Level 2 (Partial automation): human driver performs all aspects of the dynamic driving task when automated system can assist the driver with one or more driver assistance systems of both steering and acceleration/deceleration.

- SAE Level 3 (Conditional automation): automated driving system performs all aspects of driving mode-specific performance, however, the human driver must be ready to take back control to a request to intervene.

- SAE Level 4 (High automation): automated driving system performs all aspects of driving tasks, even if a human driver does not need to take back control to a request to intervene. However, the automated system can operate only in certain environments and under certain conditions.

- SAE Level 5 (Full automation): the automated system performs all driving tasks, in any environment and under all conditions that can be conducted by a human driver. (SAE International, 2018)

Kockelman et al. (2016) argue that finding the acceptable level of automation by consumers may initially be a challenge, as consumer resistance to full vehicle automation is currently being exhibited. This resistance to self-driving automation is to be expected given that the adoption and diffusion of technologies are often gradual and varied over time, individuals, and learning processes (Rogers 2010). Menon et al. (2016) found that nearly $62 \%$ of U.S. drivers are unwilling to ride in an autonomous vehicle. 
The major barrier to diffusion of self-driving vehicles seemingly may not come from the technology side, but rather from low consumer acceptance (Zhang et al., 2019). While some drivers are enthusiastic to use self-driving vehicles, others are not as willing to give up control of their vehicles (König et al., 2017). Studies indicate that technology-savvy individuals may be more accepting of automated vehicles since they tend to already have trust toward technology and a willingness to accept new technology (Bansal et al., 2016; Lavieri et al., 2017).

Early adopters of self-driving vehicles, however, will likely be businesses with high levels of vehicle miles traveled, such as the freight industry, and the rental car sector (Zmud, 2017). Waymo LLC, an American autonomous driving technology development company, currently operates a commercial selfdriving taxi service in the greater Phoenix, Arizona area. The taxis operate without a driver inside and are restricted to certain locations within Phoenix (Hawkins, 2019). In addition, Cruise, the self-driving vehicle company affiliated with General Motors and Honda, is currently testing Level 4 driverless cars in the San Francisco area (Hawkins, 2020). Ford Motor Company is planning to make its own commercially available self-driving car by 2022, although the timeframe may need to be adjusted due to the COVID pandemic (Sarabok, 2020).

\section{CONCEPTUAL FRAMEWORK AND HYPOTHESES}

Davis (1989) introduced the Technology Acceptance Model (TAM), which provides a robust framework for understanding user acceptance of new technology. According to the TAM, perceived usefulness and perceived ease of use of technology are the two main determinants of user acceptance of computer technology. Perceived usefulness refers to an individual's belief of the extent to which adopting a new technology will enhance the performance of specific tasks or activities. Perceived ease of use reflects an individual's belief concerning the extent to which using the new technology will be free of effort. The TAM also posits that perceived ease of use will have a direct impact on perceived usefulness, implying that perceived usefulness of a new technology is partially dependent upon its perceived ease of use.

Using findings and measurement scales partially from the TAM, as well as from seven other technology acceptance models, Venkatesh et al. (2003) developed the United Theory of Acceptance and Use of Technology (UTAUT). The UTAUT is one of the most comprehensive technology acceptance models, integrating eight influential acceptance models. It contains four significant predictors of user acceptance of a new technology system: performance expectancy, effort expectancy, social influence, and facilitating conditions. As defined in the UTAUT, performance expectancy is the degree to which an individual believes that using the system will help him or her to attain gains in job performance. Effort expectancy is the degree of ease associated with the use of the system. Social influence is the degree to which an individual perceives that important others believe he or she should use the new system. Finally, facilitating conditions is the degree to which an individual believes that an organizational and technical infrastructure exists to support use of the system.

There have been a number of attempts to model driver acceptance of automated vehicle technology using the TAM and the UTAUT. Hewitt et al. (2019) introduced the Autonomous Vehicle Acceptance Model (AVAM) to measure public acceptance of self-driving vehicles. The AVAM combines elements of the UTAUT and the CTAM (Car Technology Acceptance Model), developed by Osswald et al. (2012). The AVAM hypothesizes that performance expectancy, effort expectancy, attitude towards technology, social influence, self-efficacy, anxiety, and perceived safety all have a direct effect on intentions to use a selfdriving vehicle. Hewitt et al. (2019) modified the wording of individual construct items in the UTAUT to make them more relevant to self-driving vehicles rather than to technology systems. The authors then presented six levels of autonomy scenarios to allow respondents to visualize six hypothetical levels of selfdriving vehicle technologies and assessed how ratings changed for the eight predictive variables as the level of autonomy changed. However, the AVAM's proposed relationships have not been tested empirically for predicting intention to use self-driving vehicles.

Osswald et al. (2012) proposed a theoretical car technology acceptance model (CTAM) by incorporating perceived safety and anxiety related to self-driving vehicles into the TAM framework for a 
more car context-related consumer acceptance model of car technology. According to Osswald et al. (2012) perceived safety relates to the degree to which an individual believes that using car automation technology will affect his or her well-being, and anxiety assesses the degree that an individual responds with apprehension, uneasiness, or feeling of arousal related to the use of automated car technology.

Nordhoff et al. (2019) presented the Multi-Level Model on Automated Vehicle Acceptance (MAVA) as a comprehensive conceptual model that integrates different research streams to explain and predict automated vehicle acceptance. The MAVA predicts acceptance of Level 4 and Level 5 automated driving systems as defined by the SAE International (2018) taxonomy, and builds on both the UTAUT and the CTAM. The MAVA incorporates a four stage decision-making process, with twenty-eight factors at the meso and micro levels that represent seven acceptance classes. The meso-level captures domain-specific, symbolic-affective, and moral-normative factors.

This study utilizes four variables included in the UTAUT, the AVAM, the CTAM, and the MAVA to predict consumer acceptance of self-driving vehicles. The variables are facilitating conditions, performance expectancy, effort expectancy, and attitude towards a self-driving vehicle. However, unlike the UTAUT, the AVAM, the CTAM, and the MAVA, this study posits facilitating conditions as having a direct impact on both performance expectancy and effort expectancy, as hypothesized by Nordhoff et al. (2020). In addition, similar to the TAM, performance expectancy (i.e., perceived usefulness) and effort expectancy (i.e., perceived ease of use) are positioned as direct predictors of attitude towards a self-driving car (i.e., technology systems). The resulting attitude towards a self-driving vehicle is then hypothesized as having a direct impact on intention to use a self-driving vehicle, as proposed in both the TAM and the CTAM.

\section{Facilitating Conditions}

Facilitating conditions is defined in this study as the degree to which an individual believes themselves to be in possession of the resources needed to use the technology found in a self-driving vehicle, to include help menus or other support systems. Bennett et al., (2019) conclude that individuals who believe they can control events and outcomes by effort and ability have an internal locus of control that may influence their intention to use a self-driving vehicle. Hewitt et al. (2019) found that the degree of perceived facilitating conditions on self-driving vehicles declined as the level of autonomous technology increased. This finding suggests that consumers question whether the current available autonomous vehicle technology is ready for higher levels of automation in self-driving vehicles.

The impact (both direct and indirect) of facilitating conditions on consumer acceptance of self-driving vehicles has been proposed in a number of theoretical models, as well as tested in some empirical studies using respondents outside the United States. Madigan et al. (2017) surveyed Greek drivers and found that facilitating conditions had a significant effect on their intentions to use automated road transport systems. Similarly, Kaye et al. (2020) found perceived behavioural control (capability and controllability) to be a significant predictor of intentions to use highly automated cars for participants residing in Australia and France. Both the AVAM and the CTAM conceptual frameworks propose that facilitating conditions will have a direct effect on the use behavior towards a self-driving vehicle.

Nordhoff et al. (2020) found facilitating conditions to be a significant positive predictor of effort expectancy for 9,118 drivers in eight European countries, concluding that individuals who think they have the necessary resources are more likely to consider (SAE Level 3) conditionally automated vehicles easy to use. However, Nordhoff et al. (2020) did not find facilitating conditions as having a significant influence on performance expectancy of a conditionally automated vehicles (SAE Level 3) as the authors had hypothesized. Based on prior research, and as shown in Figure 1, the following hypotheses are proposed:

\section{H1: Facilitating Conditions has a positive effect on Performance Expectancy.}

H2: Facilitating Conditions has a positive effect on Effort Expectancy. 
FIGURE 1

PREDICTOR MODEL FOR THE ADOPTION OF SELF-DRIVING VEHICLES

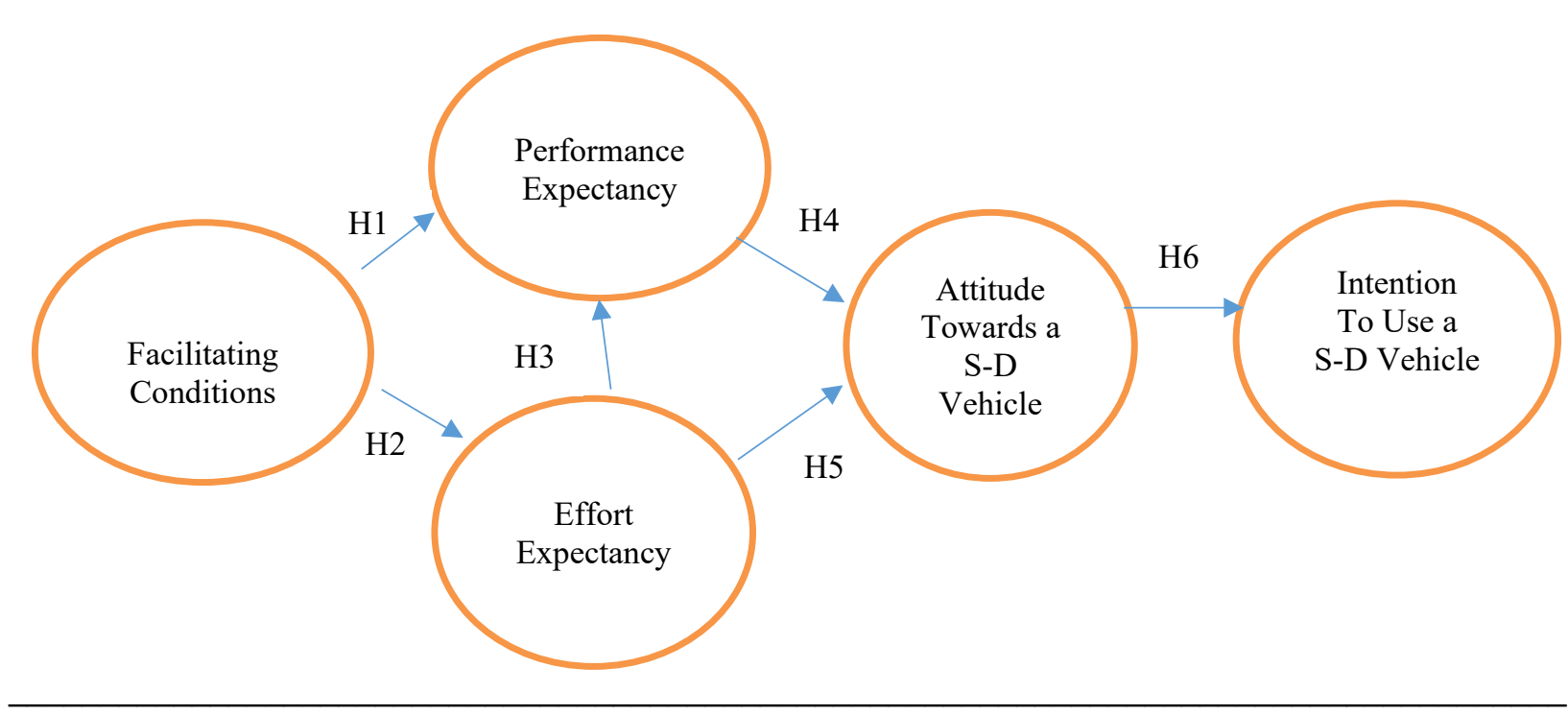

Performance Expectancy

Performance expectancy is defined in this study as the level of belief an individual has that a selfdriving vehicle will help attain goals in driving performance (i.e., improved safety, better gas mileage, reduced stress). Kaur and Rampersad (2018) argue that the performance of self-driving vehicles is hard to predict, given the advanced technology such as infrared sensors, inertial navigation systems, and ultrasonic sensors.

Scholars have empirically validated the predictive relationship of performance expectancy on attitude. The TAM posits perceived usefulness as a direct predictor of an individual's attitude towards using computer technology. Erskine et al. (2020) found performance expectancy to have a significant positive effect on attitude towards a self-driving vehicle. Based on prior research, and as shown in Figure 1, the following hypothesis is proposed:

H4: Performance Expectancy has a positive effect on Attitude Towards a Self-Driving Vehicle.

\section{Effort Expectancy}

For this study, effort expectancy is defined as the level of perceived ease associated with the use of a self-driving vehicle. Kyriakidis et al. (2014) found from a public opinion questionnaire that self-driving vehicles were perceived to be easier to use than manual driving vehicles. The TAM positions perceived ease of use as a predictor of perceived usefulness.

Recent studies have demonstrated the positive influence of perceived ease of use on the perceived usefulness of self-driving vehicles (Herrenkind et al., 2019; Zhang et al., 2019). Nordhoff et al., (2020) suggest that these findings imply that drivers who consider automated cars to be easy to use (i.e., effort expectancy) are more likely to consider automated cars useful (i.e., performance expectancy). However, Nordhoff et al., (2020) hypothesized, but did not find, effort expectancy as having a significant effect on performance expectancy of conditionally automated (SAE Level 3) vehicles among European drivers.

The TAM also posits that perceived ease of use will have a direct effect of an individual's attitude towards using computer technology. Erskine et al. (2020) found effort expectancy to have a significant positive effect on attitude towards a self-driving vehicle. Based on prior research, and as shown in Figure 1, the following hypotheses are proposed: 


\section{H3: Effort Expectancy has a positive effect on Performance Expectancy.}

\section{H5: Effort Expectancy has a positive effect on Attitude Towards a Self-Driving Vehicle.}

\section{Attitude Towards a Self-Driving Vehicle}

An individual's attitude is defined in this study as the degree to which a person has a favorable or unfavorable evaluation of using automated vehicle technology. Rogers (2010) argues that innovation adoption decisions are determined by the overall attitude of potential users toward innovations. Therefore, the diffusion of self-driving vehicles is likely to be significantly affected by the public's attitude towards them. Several studies have theorized the importance of attitude in technology acceptance research. The TAM posits that an individual's attitude toward using computer technology will significantly influence his/her intentions towards using the technology. Aggelidis and Chatzoglou (2009) came to the same conclusion concerning attitude and the use of information technology in the healthcare sector.

Acheampong et al. (2019) found a positive relationship between favorable attitudes towards technology in general and perception of the benefits of self-driving vehicles. Osswald et al. (2012) included attitude towards using technology as a predictor of intention to use self-driving vehicles in their theoretical model (CTAM). Jing et al., (2020) also propose in their theoretical model that attitude towards self-driving vehicles will directly impact acceptance of autonomous vehicles. Moreover, Charness et al. (2018) and Buckley et. al. (2018) both conclude that attitudes towards self-driving technology can significantly impact the adoption of self-driving vehicles. Finally, Kaye et al. (2020) found that the attitude towards using conditionally automated cars was the strongest predictor of intentions to use conditionally automated cars. Based on prior research, and as shown in Figure 1, the following hypothesis is proposed:

H6: Attitude Towards a Self-Driving Vehicle has a positive effect on Intention to Use a Self-Driving Vehicle.

\section{METHODOLOGY}

\section{Data Collection}

Data were collected from 1,050 respondents using Qualtrics. The demographic profile of respondents appears to be reflective of the general population. Of the sample respondents, $49.3 \%$ were men and $50.7 \%$ were women. Regarding age of respondent, $21.6 \%$ were $18-29 ; 25.5 \%$ were $30-44 ; 25.9 \%$ were $45-60$; and $27 \%$ were 60 or older. Respondents were generally well educated, with $35.7 \%$ having a high school degree; $26.9 \%$ obtaining an associate or bachelor's degree; and $11.4 \%$ possessing at least a master's degree. Approximately $49 \%$ of respondents reported household income of $\$ 50,000$ or higher.

An 18-item questionnaire was developed in accordance with the framework of the proposed model in Figure 1. The questionnaire assessed respondents' beliefs concerning self-driving vehicles. Respondents were informed that for the purpose of this research, a self-driving vehicle is defined as follows: "Your car is fully self-driving only on large, multi-lane highways. You must manually steer and accelerate/decelerate when on minor roads, but upon entering a highway the car can take full control and can steer, accelerate/decelerate and switch lanes as appropriate. The car does not rely on your input at all while on the highway. Upon reaching the exit of the highway, the car indicates that you must retake control of the steering and speed control" (Hewitt et al. p. 522, 2019). The above definition was used by Hewitt et al. (2019) in their description of a Level 4 autonomy scenario to survey respondents. In this study, the term "self-driving" replaced "autonomously" in the definition, as it was felt that respondents could better relate to and visualize self-driving vehicles vs. autonomous vehicles.

\section{Measurement Scales}

The measurement scales utilized in this study were all five-point Likert-type scales ranging from "Strongly Disagree" (1) to "Strongly Agree" (5). Facilitating Conditions, Performance Expectancy, Effort Expectancy, and Attitude Towards a Self-Driving Vehicle were all three-item scales. Intention to Use a 
Self-Driving Vehicle was a two-item scale. The specific measurement items used within each measurement scale were the ones developed by Hewitt et al. (2019) and adapted from UTAUT. (See Appendix)

\section{Data Analysis and Results}

The internal reliability of the measurement scales were first assessed. The Cronbach's alpha reliabilities for each construct are as follows: Facilitating Conditions (.800), Performance Expectancy (.847), Effort Expectancy (.875), Attitude Towards a Self-Driving Vehicle (.894), and Intention to Use a Self-Driving Vehicle (.869). All reliabilities reflected excellent internal consistencies, with all values above the threshold value of .60 (Fornell \& Larcker, 1981; Bagozzi \& Yi, 1988).

The proposed theoretical model was then tested using Structural Equation Modeling (SEM). Three types of information were considered in assessing the model fit: chi-square, measurement error, and fit indices. Given that chi-square values tend to be sensitive to sample size and are likely to be significant if large datasets are utilized, chi-square is not an absolute criterion in evaluating model fit. A second criterion that was examined was measurement error, namely RMSEA (root-mean-square error of approximation) and RMR (Root Mean Square Residual). The final piece of evidence examined were the fit indices of CFI (Comparative Fit Index), IFI (Incremental Fit Index), NFI (Normed Fit Index), and NNFI (Non-Normed Fit Index).

As shown in Table 1, the overall model fit was very good. Although the Chi-Square was significant at .01 level, the measurement error, indicated by RMSEA and RMR, was low at .06 and .03 respectively. In addition, all the fit indices, including CFI $=.99, \mathrm{IFI}=.99, \mathrm{NFI}=.99, \mathrm{NNFI}=.99$, were all well above the acceptable cut-off values (Hu and Bentler, 1999). Therefore, the proposed theoretical model was accepted.

TABLE 1

PROPOSED THEORETICAL MODEL TESTING

\begin{tabular}{|c|c|c|c|c|c|c|c|c|c|c|}
\hline & $\begin{array}{c}\text { Chi- } \\
\text { Square }\end{array}$ & DF & Sig. & RMSEA & RMR & CFI & IFI & NFI & NNFI & Decision \\
\hline $\begin{array}{c}\text { Structure } \\
\text { Model }\end{array}$ & 351.67 & 71 & .000 & .06 & .03 & .99 & .99 & .99 & .99 & Accept \\
\hline
\end{tabular}

\section{Structural Model Analyses}

Structural equation modeling (SEM) was also used to test the relationships between the theoretical constructs, as well as the hypotheses. Raw data were used as input, and the program analyzed the covariance matrix calculated from the raw data by using Maximum Likelihood (ML) estimation. Hypotheses were tested through path analysis. The significance of path coefficients in the model provides support for the hypothesized relationship (Bentler, 1989).

H1 proposed a significant positive relationship between Facilitating Conditions and Performance Expectancy. As shown in Table 2, H1 was supported $(\beta=0.48, \mathrm{p}<.01)$. H2 proposed a significant positive relationship between Facilitating Conditions and Effort Expectancy. H2 was also supported $(\beta=0.93, p<$ $.01)$. H3 proposed Effort Expectancy would have significant positive effect on Performance Expectancy. $\mathrm{H} 3$ was supported $(\beta=0.52, \mathrm{p}<.01)$. 
TABLE 2

HYPOTHESES TESTING

\begin{tabular}{|c|c|c|c|c|c|c|}
\hline & H1 & $\mathrm{H} 2$ & H3 & H4 & H5 & H6 \\
\hline Path & $\begin{array}{c}\text { Facilitating } \\
\rightarrow \\
\text { Performance }\end{array}$ & $\begin{array}{c}\text { Facilitating } \\
\rightarrow \\
\text { Effort } \\
\end{array}$ & $\begin{array}{c}\text { Effort } \\
\rightarrow \\
\text { Performance }\end{array}$ & $\begin{array}{c}\text { Performance } \\
\rightarrow \\
\text { Attitude }\end{array}$ & $\begin{array}{c}\text { Effort } \\
\rightarrow \\
\text { Attitude }\end{array}$ & $\begin{array}{c}\text { Attitude } \\
\rightarrow \\
\text { Intention }\end{array}$ \\
\hline Coefficient & $.48^{*}$ & $.93 *$ & $.52 *$ & $.40^{*}$ & $.52 *$ & .96 \\
\hline T-Value & 3.70 & 25.62 & 3.00 & 8.12 & 10.64 & 37.68 \\
\hline
\end{tabular}

*Significant at .01 level

H4 proposed a significant positive relationship between Performance Expectancy and Attitude Towards a Self-Driving Vehicle. As shown in Table 2, H4 was also supported $(\beta=0.40, p<.01)$. H5 proposed Effort Expectancy would have significant positive effect on Attitude Towards a Self-Driving Vehicle. H5 was supported $(\beta=0.52, p<.01)$. Finally, as shown in Table 2 , H6 proposed a significant positive relationship between Attitude Towards a Self-Driving Vehicle and Intention to Use a Self-Driving Vehicle. H6 was supported $(\beta=0.96, \mathrm{p}<.01)$.

\section{DISCUSSION/IMPLICATIONS}

This study examined factors that likely will impact consumer adoption of self-driving vehicles when these vehicles become available in the U.S. The theoretical basis of this study was derived from a number of conceptual and empirically tested technology adoption models. The findings show that facilitating conditions (i.e., help menus, manuals, and other supporting resources) have a direct and positive effect on both performance expectancy (i.e., usefulness) and effort expectancy (i.e., ease of use) as they relate to a self-driving vehicle. Moreover, the resulting performance expectancy and effort expectancy have a strong influence on a consumer's attitude towards a self-driving vehicle.

The findings demonstrate a number of important implications related to the development and marketing of self-driving vehicles. To begin with, facilitating conditions are of paramount importance in the consumer adoption process. Potential buyers need to feel comfortable that there is technology and other resources available that will assist them in the operation of the self-driving vehicle. These available resources should enhance a potential buyer's belief that; 1) the self-driving vehicle will help attain goals in driving performance (performance expectancy), and 2) the level of perceived ease associated with operating the self-driving vehicle (effort expectancy) is sufficient. Manufacturers and marketers should emphasize the resources available to help drivers operate autonomous vehicles.

In addition, given that effort expectancy is an important factor influencing both performance expectancy and attitude towards a self-driving vehicle, salespeople at auto dealerships should be trained to explain the functionalities of the vehicle and stress how easy it is to use the automated technology in the vehicle. This seemingly will not only enhance perceived safety, gas mileage rating, and other performance metrics important to the potential buyer, but should also have a positive effect on the buyer's overall attitude towards the vehicle. Furthermore, the strategic marketing of self-driving vehicles based on safety, gas mileage, as well as ease of-use, should lead to a more positive attitude towards self-driving vehicles.

Finally, consumer attitude towards a self-driving vehicle will likely be an important factor in determining the intention to actually use a self-driving vehicle. It is imperative that marketers provide ample and accurate information to allow consumers to make informed purchase decisions regarding self-driving vehicles. Self-driving vehicles are on the horizon in the U.S. and helping potential buyers of these vehicles to form a positive attitudes towards them will be important for product adoption and diffusion into the marketplace. 


\section{LIMITATIONS AND FUTURE RESEARCH}

One limitation of this study is that "intention to use" is a self-reported response that may differ significantly from actual use at a later date. Once self-driving vehicles are commercially available, intentions to use or attitudes toward a self-driving vehicle may change either more positively or negatively. Another limitation is that findings were not based on respondent usage motives. For example, the factors impacting intention to use a self-driving vehicle is likely impacted by whether an individual's primary motive for using this type of vehicle is for utilitarian reasons (e.g., safety, fuel efficiency, stress free driving) or for hedonic reasons (e.g., enjoyment, fun, impressing family and friends).

Additional research is needed to assess cultural differences that could influence the generalizability of consumer adoption models for self-driving vehicles. McCoy et al. (2007) argue that technology acceptance models, such as the TAM, may not be applicable to all people, and that results may differ depending on respondents' cultural orientation. Given that major automobile manufacturers market their vehicles globally, a cross-cultural analysis would be beneficial. Further research should also focus on testing more complex models for predicting usage intention for self-driving vehicles. Finally, additional studies are needed to examine how intention to use a self-driving vehicle may differ by personality, lifestyle, gender, education level, location (urban vs. rural), and driving experience.

\section{REFERENCES}

Acheampong, R.A., \& Cugurullo, F. (2019). Capturing the behavioural determinants behind the adoption of autonomous vehicles: Conceptual frameworks and measurement models to predict public transport, sharing and ownership trends of self-driving cars. Transportation Research Part F: Traffic Psychology and Behaviour, 62, 349-375.

Aggelidis, V.P., \& Chatzoglou, P.D. (2009). Using a modified technology acceptance model in hospitals. International Journal of Medical Informatics, 78(2), 115-126.

Bagozzi, R.P., \& Yi, Y. (1988). On the evaluation of structural equation models. Academy of Marketing Science, 16(1), 74-94.

Bansal, P., Kockelman, K.M., \& Singh, A. (2016). Assessing public opinions of and interest in new vehicle technologies: An Austin perspective. Transportation Research Part C: Emerging Technologies, 67, 1-14.

Bennett, R., Vijaygopal, R., \& Kottasz, R. (2019). Attitudes towards autonomous vehicles among people with physical disabilities. Transportation Research Part A: Policy and Practice, 127, 1-17.

Bentler, P.M. (1989). EQS: Structural Equations Program Manual (version 3.0.). Los Angeles: BMDP Statistical Software Inc.

Buckley, L., Kaye, S-A., \& Pradhan, A.K. (2018). Psychosocial factors associated with intended use of automated vehicles: A simulated driving study. Accident Analysis and Prevention, 15, 202-208.

Charness N., Yoon, J.S., Souders, D., Stothart, C., \& Yehnert, C. (2018). Predictors of attitudes toward autonomous vehicles: The roles of age, gender, prior knowledge, and personality. Frontiers in Psychology, pp. 1-9. https://doi.org/10.3389/fpsyg.2018.02589

Davis, F.D. (1989). Perceived usefulness, perceived ease of use, and user acceptance of information technology. MIS Quarterly, 13(3), 319-340.

Ensuring American Leadership in Automated Vehicle Technologies. (2020, January). A Report by the National Science \& Technology Council and The United States Department of Transportation.

Erskine, M.A., Brooks, S., Greerand, T.H., \& Apigian, C. (2020). From driver assistance to fullyautonomous: Examining consumer acceptance of autonomous vehicle technologies. Journal of Consumer Marketing, 37(7), 883-894.

Fornell, C., \& Larcker, D.F. (1981). Evaluating structural equation models with unobservable variables and measurement error. Journal of Marketing Research, 18(1), 39-50. 
Hawkins, A. (2019). Waymo's driverless car: Ghost-riding in the back seat of a robot taxi. The Verge. Retrieved from https:/www.theverge.com/2019/12/9/21000085/waymo-fully-driverless-car-selfdriving-ride-hail-service-phoenix-arizona

Hawkins, A. (2020). Cruise is now testing fully driverless cars in San Francisco. The Verge. Retrieved from https://www.theverge.com/2020/12/9/22165597/cruise-driverless-test-san-francisco-selfdriving-level-4

Herrenkind, B., Nastjuk, I., Brendel, A.B., Trang, S., \& Kolbe, L.M. (2019). Young people's travel behavior - Using the life-oriented approach to understand the acceptance of autonomous driving. Transportation Research Part D: Transport and Environment, 74, 214-233.

Hewitt, C., Amanatidis, T., Politis, I., \& Sarkar, A. (2019, July). Assessing public perception of selfdriving cars: Autonomous vehicle acceptance model. $24^{\text {th }}$ International Conference on Intelligent User Interfaces. https://doi.org/10.1145/3301275.3302268

Hu, L., \& Bentler, P.M. (1999). Cutoff criteria for fit indexes in covariance structure analysis: Conventional criteria versus new alternatives. Structural Equation Modeling, 6(1), 1-55.

Jing, P, Xu, G., Chen, Y., Shi, Y., \& Zhan, F. (2020). The determinants behind the acceptance of autonomous vehicles: A systematic review. Sustainability, 12(5). https://doi.org/10.3390/su12051719

Kaplan, S., Gordon, B., El Zarwi, F., Walker, J.L., \& Zilberman, D. (2019). The future of autonomous vehicles: Lessons from the literature on technology adoption. Applied Economic Perspectives and Policy, 41(4), 583-597.

Kaur, K., \& Rampersad, G. (2018). Trust in driverless cars: Investigating key factors influencing the adoption of driverless cars. Journal of Engineering and Technology Management, 48, 87-96.

Kaye, S-A., Lewis, I., Forward, S., \& Delhomme, P. (2020). A priori acceptance of highly automated cars in Australia, France, and Sweden: A theoretically-informed investigation guided by the TPB and UTAUT. Accident Analysis \& Prevention, 137. doi:10.1016/j.aap.2020.105441

Kockelman, K., Loftus-Otway, L., Stewart, D., Nichols, A., Wagner, W., Li, J., . . Liu, J. (2016). Best Practices Guidebook for Preparing Texas for Connected and Automated Vehicles (No. 0-6849P1). Texas, Austin: Center for Transportation Research.

König, M., \& Neumayr, L. (2017). Users' resistance towards radical innovations: The case of the selfdriving car. Transportation Research Part F: Traffic Psychology and Behavior, 44, 42-52.

Kyriakidis, M., Happee, R., \& De Winter, J.C.F. (2014). Public opinion on automated driving: Results of an international questionnaire among 5,000 respondents. Transportation Research Part F: Traffic Psychology and Behavior, 32, 127-140.

Lavieri, P.S., Garikapati, V.M., Bhat, C.R., Pendyala, R.M., Astroza, S., \& Dias, F.F. (2017). Modeling individual preferences for ownership and sharing of autonomous vehicle technologies. Transportation Research Record: Journal of the Transportation Research Board, 2665(1), 1-10.

Madigan, R., Louw, T., Wilbrink, M., Schieben, A., \& Merat, N. (2017). What influences the decision to use automated public transport? Using UTAUT to understand public acceptance of automated road transport systems. Transportation Research Part F: Traffic Psychology and Behaviour, 50, 55-64.

McCoy, S., Galletta, D.F., \& King, W.R. (2007). Applying TAM across cultures: The need for caution. European Journal of Information Systems, 16(1), 81-90.

Menon, N., Pinjari, A., Zhang, Y., \& Zou, L. (2016, January 10-14). Consumer perception and intended adoption of autonomous-vehicle technology: Findings from a university population survey. In Proceedings of the Transportation Research Board 95th Annual Meeting. Washington, DC, USA.

National Highway Traffic Safety Administration. (2020). Automated vehicles for safety. Retrieved from https://www.nhtsa.gov/technology-innovation/automated-vehicles-safety

Nordhoff, S., De Winter, J., Kyriakidis, M., Van Arem, B., \& Happee, R. (2018). Acceptance of driverless vehicles: Results from a large cross-national questionnaire study. Journal of Advanced Transportation, pp. 1-22. Retrieved from https://www.hindawi.com/journals/jat/2018/5382192/ 
Nordhoff, S., Kyriakidis, M., van Arem, B., \& Happee, R. (2019). A multi-level model on automated vehicle acceptance (MAVA): A review-based study. Theoretical Issues in Ergonomics Science, 20(6), 682-710. DOI: 10.1080/1463922X.2019.1621406

Nordhoff, S., Louw, T., Innamaa, S., Lethonen, E., Beuster, A., Torrao, G., . . Merat, N. (2020). Using the UTAUT2 model to explain public acceptance of conditionally automated (L3) cars: A questionnaire study among 9,118 car drivers from eight European countries. Transportation Research Part F: Traffic Psychology and Behaviour, 74, 280-297.

Osswald, S., Wurhofer, D., Trosterer, S., Beck, E., \& Tscheligi, M. (2012). Predicting information technology usage in the car: Towards a car technology acceptance model. Automotive UI, pp. 5158.

Rogers, E.M. (2010). Diffusion of Innovations. Simon and Schuster. New York: The Free Press.

SAE International. (2018). SAE International Releases Updated Visual Chart for Its "Levels of Driving Automation” Standard for Self-Driving Vehicles. Retrieved from https://www.sae.org/news/pressroom/2018/12/sae-international-releases-updated-visual-chart-for-its- $\%$ E2\%80\%9Clevels-ofdriving-automation $\% \mathrm{E} 2 \% 80 \% 9 \mathrm{D}$-standard-for-self-driving-vehicles

Sarabok, G. (2020). Levels of self-driving cars explained. Towards Data Science. Retrieved from $\mathrm{https}$ ://towardsdatascience.com/levels-of-self-driving-cars-explained-24454463b8eb

Venkatesh, V., Morris, M., Davis, G., \& Davis, F. (2003). User acceptance of information technology: Toward a unified view. MIS Quarterly, 27, 425-478.

Zhang, T., Tao, D., Qu, X., Zhang, X., Lin, R., \& Zhang, W. (2019). The roles of trust and perceived risk in public's acceptance of automated vehicles. Transportation Research Part C: Emerging Technologies, 98, 207-220.

Zmud, J. (2017, July 11-14). Market Acceptance and Demand: Data Capture and Analysis Techniques to Examine Behavioral Responses to AVs. Automated Vehicle Symposium. San Francisco, CA.

\section{APPENDIX: MEASUREMENT SCALES}

\section{Facilitating Conditions* (Hewitt et al., 2019)}

1. I would have adequate control over the journey to my destination.

2. I have the knowledge necessary to use the vehicle.

3. The vehicle and infrastructure necessary to use the vehicle are practically feasible.

Performance Expectancy* (Hewitt et al., 2019)

1. Using the vehicle would enable me to reach my destination quickly.

2. Using the vehicle would enable me to reach my destination cost efficiently.

3 . Using the vehicle would enable me to reach my destination safely.

Effort Expectancy* (Hewitt et al., 2019)

1. I would find the vehicle easy to use.

2. My interaction with the vehicle would be clear and understandable.

3. It would be easy for me to learn to use the vehicle.

Attitude Towards a Self-Driving Vehicle* (Hewitt et al., 2019)

1. Using the vehicle would be a good idea.

2. The vehicle would make driving more interesting.

3. Using the vehicle would be fun.

Intention to Use a Self-Driving Vehicle* (Hewitt et al., 2019)

1. Given that I had access to the vehicle, I predict that I would use it.

2. If the vehicle becomes available to me, I plan to obtain and use it.

*Likert-type items anchored by $1=$ Strongly Disagree; $5=$ Strongly Agree 